\title{
Transaxonal degenerations of cerebellar connections: the value of anatomical knowledge
} Degenerações transaxonais das conexões cerebelares: o valor do conhecimento anatômico Mariana Trombetta de Lima RAEDER, Eduardo Pontes REIS', Brunno Machado CAMPOS², Igor Aloísio Garcez ZAMILUTE1, Marcondes Cavalcante FRANÇA JÚNIOR², Fabiano REIS1

\begin{abstract}
Transaxonal degenerations result from neuronal death or the interruption of synaptic connections among neuronal structures. These degenerations are not common but may be recognized by conventional magnetic resonance imaging. Objective: The learning objectives of this review include recognition of the imaging characteristics of transaxonal degenerations involving cerebellar connections, the identification of potential encephalic lesions that can lead to these degenerations and correlation of the clinical manifestations with imaging findings that reflect this involvement. Methods: In this report, we review the neuroanatomical knowledge that provides a basis for identifying potential lesions that can result in these degenerations involving cerebellar structures. Results: Hypertrophic olivary degeneration results from an injury that interrupts any of the components of the Guillain-Mollaret triangle. In this work, we describe cases of lesions in the dentate nucleus and central tegmental tract. The crossed cerebellar diaschisis presents specific imaging findings and clinical correlations associated with its acute and chronic phases. The Wallerian degeneration of the middle cerebellar peduncle is illustrated by fiber injury of the pontine cerebellar tracts. A T2-hyperintensity in the dentate nucleus due to a thalamic acute lesion (in ventral lateral nuclei) is also described. Each condition described here is documented by MRI images and is accompanied by teaching points and an anatomical review of the pathways involved. Conclusion: Neurologists and radiologists need to become familiar with the diagnosis of these conditions since their presentations are peculiar and often subtle, and can easily be misdiagnosed as ischemic events, degenerative disease, demyelinating disease or even tumors.
\end{abstract}

Keywords: Status Epilepticus; Middle Cerebellar Peduncle; Olivary Nucleus; Cerebellar Nuclei; Red Nucleus.

\section{RESUMO}

Degenerações transaxonais resultam da morte neuronal ou da interrupção de conexões sinápticas entre estruturas neurais. Essas degenerações não são comuns, mas podem ser reconhecidas por imagens de ressonância magnética convencional. Objetivo: Os objetivos de aprendizado desta revisão incluem o reconhecimento das características de imagem de degenerações transaxonais envolvendo conexões cerebelares, a identificação de possíveis lesões encefálicas que podem levar a essas degenerações e a correlação das manifestações clínicas com os achados de imagem que refletem esse envolvimento. Métodos: Neste artigo, revisamos conhecimentos neuroanatômicos que fornecem a base para identificar possíveis lesões que podem resultar nessas degenerações envolvendo estruturas cerebelares. Resultados: A degeneração olivar hipertrófica resulta de uma lesão que interrompe algum dos componentes do triângulo de Guillain-Mollaret. Neste trabalho, descrevemos casos de lesões no núcleo denteado e no trato tegmentar central. A diásquise cerebelar cruzada apresenta achados de imagem específicos e correlações clínicas associadas às suas fases aguda e crônica. A degeneração walleriana dos pedúnculos cerebelares médios é ilustrada pela lesão dos tratos pontino-cerebelares. Uma hiperintensidade em T2 do núcleo denteado devido a uma lesão talâmica aguda (no núcleo ventrolateral) também é descrita. Cada condição aqui descrita é documentada por imagens de ressonância magnética e é acompanhada por pontos didáticos e uma revisão anatômica das vias envolvidas. Conclusão: Neurologistas e radiologistas precisam estar familiarizados com o diagnóstico dessas condições, uma vez que suas apresentações são peculiares e frequentemente sutis, e podem ser facilmente equivocadamente diagnosticadas como lesões isquêmicas, doenças degenerativas, desmielinizantes, ou mesmo tumorais.

Palavras-chave: Estado Epiléptico; Pedúnculo Cerebelar Médio; Núcleo Olivar; Núcleos Cerebelares; Núcleo Rubro.

\footnotetext{
1 Universidade Estadual de Campinas, Departamento de Radiologia, Campinas SP, Brazil.

Universidade Estadual de Campinas, Departamento de Neurologia, Campinas SP, Brazil.

Mariana Trombetta de Lima RAEDER (D) https://orcid.org/0000-0002-7404-5362; Eduardo Pontes REIS (D) https://orcid.org/0000-0001-5110-457X; Brunno Machado CAMPOS (D) https://orcid.org/0000-0003-1261-8257; Igor Aloísio Garcez ZAMILUTE (D) https://orcid.org/0000-0002-2959-3511; Marcondes Cavalcante FRANÇA JÚNIOR (D) https://orcid.org/0000-0003-0898-2419; Fabiano REIS (D) https://orcid.org/0000-0003-2256-4379

Correspondence: Fabiano Reis; E-mail:fabianoreis2@gmail.com

Conflict of interest: There is no conflict of interest to declare.
}

Received on August 06, 2019; Received in its final form on February 03, 2020; Accepted on February 10, 2020. 


\section{INTRODUCTION}

Transaxonal degenerations result from neuronal death or interruption of the synaptic connections that link neural structures. These degenerations are uncommon and can be recognized by conventional magnetic resonance imaging (MRI) and diffusion tensor imaging (DTI) ${ }^{1,2,3}$. Truncal ataxia, dysarthria, increased muscle tone, and palatal myoclonus may result from these degenerations. Based on the neuroanatomical knowledge reviewed in this paper, it is possible to identify potential lesions that can result in these degenerations involving cerebellar connections.

The aim of this pictorial essay is to review the main findings associated with different cerebellar degenerations since correct identification is essential for avoiding a wrong diagnosis. In order to illustrate the anatomical pathways involved in the Guillain-Mollaret triangle (GMT), we present a series of cases of hypertrophic olivary degeneration (HOD) caused by a central tegmental tract lesion and by a dentate nucleus lesion, transaxonal degeneration caused by a dentatorubrothalamic tract lesion, chronic crossed cerebellar diaschisis (CCD), acute transient crossed cerebellar diaschisis, and Wallerian degeneration of the middle cerebellar peduncles.

\section{MRI SETTINGS}

A retrospective study of the cases was performed and images from the didactic collection from the Unicamp Hospital concerning the last five years were analyzed.

All participants underwent a routine brain protocol MRI on a $1.5 \mathrm{~T}$ or $3 \mathrm{~T}$ scanner.

The patients had given their informed consent.

The literature review was performed by searching the following keywords on PubMed database: "Guillain-Mollaret triangle", "hypertrophic olivary degeneration”, "transaxonal degeneration", "crossed cerebellar diaschisis", and "Wallerian degeneration". The articles included were the publications from journals with higher impact indices.

\section{CLINICAL IMAGES}

\section{Hypertrophic olivary degeneration}

\section{Hypertrophic olivary degeneration caused by a central tegmental tract lesion}

HOD is a transneuronal degeneration of the inferior olivary nucleus that occurs after disruption of the dentatorubro-olivary pathway or GMT ${ }^{4,5,6}$. The GMT is defined by three gray matter nuclei: the dentate nucleus, the red nucleus, and the inferior olivary nucleus. These structures are connected by three pathways:
- Olivary-dentate or olivocerebellar fibers that arise from the inferior olivary nucleus and cross the midline through the inferior cerebellar peduncle to reach the contralateral dentate nucleus.

- Dentatorubral fibers that arise from the contralateral dentate nucleus and pass through the superior cerebellar peduncle and decussate within the midbrain to reach the opposite red nucleus.

- The ipsilateral central tegmental or rubro-olivary tract that descends from the red nucleus to the inferior olivary nucleus ${ }^{7.8}$ (Figure 1).

A 57-year-old female patient with a history of surgically treated breast cancer presented with seizures in the emergency room. After undergoing computed tomography (CT) of the cranium, she was diagnosed as having an expansive metastatic lesion in the topography of the central tegmental tract that shifted this structure contralaterally. About six months later, MRI revealed hyperintensity and an increased volume of the ipsilateral medullary olive, a characteristic feature of HOD (Figure 2) and the lesion in the central tegmental tract showed low tiny hypointense foci suggestive of petechial hemorrhages on SWI (susceptibility weighted imaging).

HOD is a rare transynaptic degeneration caused by injury to the dentato-rubro-olivary tract and results in the disconnection of afferent axons to the inferior olivary nucleus. The latter nucleus is part of the dentato-rubro-olivary pathway,

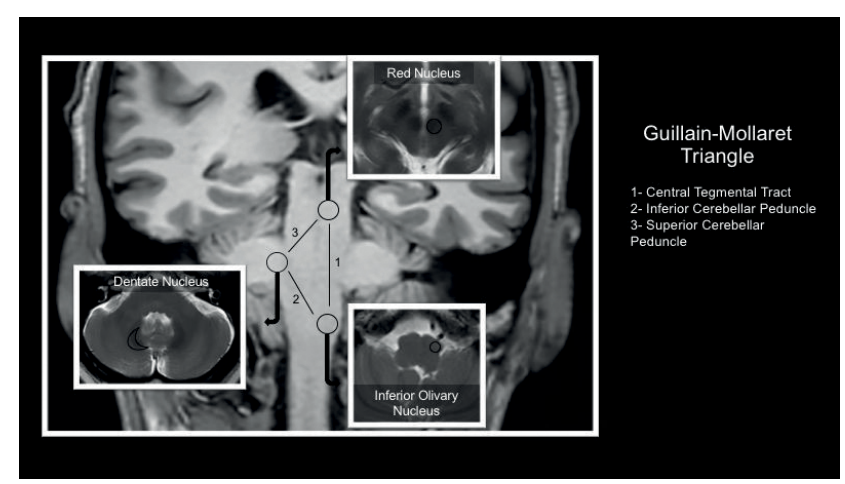

Figure 1. Coronal T1-weighted MR image with schematic of the Guillain-Mollaret triangle.

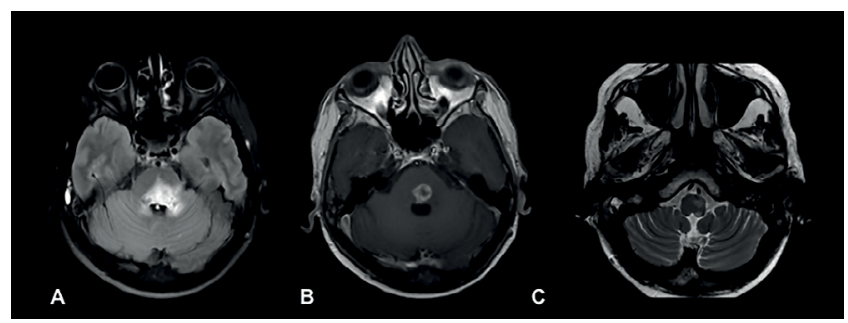

Figure 2. Axial FLAIR (A), T1-post-gadolinium (B), and T2 weighted images (C): Expansive lesion in the left posterior aspect of the pons, with central necrosis and vasogenic edema. Left hypertrophic olivary degeneration caused by a central tegmental tract lesion. 
also known as the Guillain-Mollaret triangle, which projects its efferent fibers through the superior cerebellar peduncle to the contralateral red nucleus. Fibers from the red nucleus are sent to the ipsilateral inferior olivary nucleus via the central tegmental tract. The inferior olivary nucleus in turn connects with the contralateral dentate nucleus through efferent fibers via the inferior cerebellar peduncle, thus forming a triangle. Injury to any of these components may result in axonal interruption to the inferior olivary nucleus and lead to its degeneration.

HOD is an atypical pattern of trans-synaptic (or transneuronal) degeneration since enlargement rather than atrophy occurs. Histopathological analysis of these autopsy specimens has demonstrated an unusual pattern of neuronal cytoplasmic vacuolization, hypertrophy of astrocytes, increased gliosis, and demyelination of the olivary nucleus leading to hypertrophy'. When the lesions are restricted to the central tegmental tract, HOD is ipsilateral ${ }^{5}$. When the dentate nucleus or the superior cerebellar peduncle are affected, HOD is contralateral. If both central tegmental tracts are injured or the lesions involve the superior cerebellar peduncle and the contralateral central tegmental tract simultaneously, then HOD is bilateral. A T2 hyperintense tumefactive lesion observed by MRI in the anterolateral portion of the bulb (olive) without contrast enhancement is suggestive of HOD.

\section{Hypertrophic olivary degeneration caused by a dentate nucleus lesion}

A 59-year-old male patient with HIV infection for 20 years presented with a paracoccidioidomycosis infection of the central nervous system (CNS) in the early years of HIV infection. Routine MRI of the brain showed a lesion in the left dentate nucleus and consequent contralateral HOD (Figure 3) caused by interruption of the dentate-rubro-olivary pathway (Guillain-Mollaret triangle) ${ }^{10,11}$. Clinically, the patient showed movement disorder characterized by hyperkinesia ${ }^{12}$.

The inferior olivary nucleus is related to motor learning mechanisms and its injury causes synchronous tremor of the palate (palate myoclonus) or other dentatorubral tremor ${ }^{1,13}$. The red nucleus coordinates the automatic and voluntary movements and its lesion leads to contralateral hyperkinesia
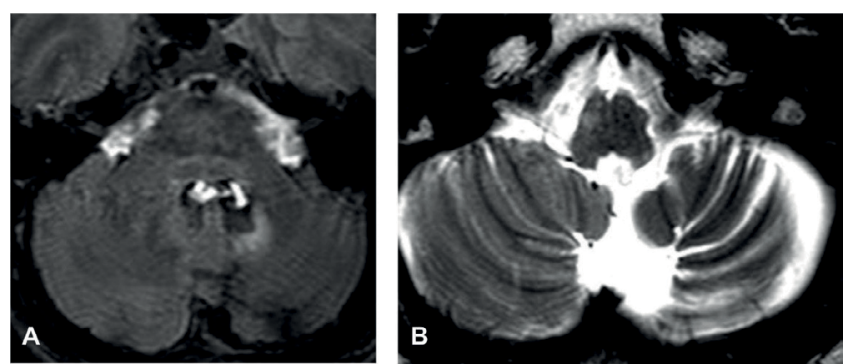

Figure 3. Axial FLAIR image (A) demonstrates left dentate nucleus hyperintensity and axial T2 image (B) shows hyperintensity in the right inferior olivary nucleus. (chorea and athetosis). When there is an injury to the dentate nucleus, movement coordination and planning abilities are compromised (dysmetria) ${ }^{14,15}$.

\section{Transaxonal degeneration caused}

\section{by a dentatorubrothalamic tract lesion}

A 77-year-old woman was admitted following a suddenonset of left leg and arm palsy, ipsilateral dysmetria and dysdiadochokinesia. MRI showed recent infarction in the right lateral thalamus in addition to a signal change in the right dentate nucleus, secondary to transaxonal degeneration of the dentatorubrothalamic tract (Figure 4).

The dentatorubrothalamic tract is the major efferent cerebellar pathway arising from the dentate nucleus and decussating to the contralateral red nucleus and thalamus (classic pathway). However, the hemispheric cerebellar output influences bilateral limb movements once there is a corresponding non-decussating pathway. Recent studies have shown that a smaller bundle of fibers located in the dorsal part of the superior cerebellar peduncle does not decussate but reaches the ipsilateral red nucleus and thalamus ${ }^{16}$. Consequently, the hemispheric cerebellar output influences bilateral limb movements and not only contralateral, as previously described in the literature. In the case described above, the patient had typical clinical symptoms. She remains in clinical follow-up and symptomatic, with left dysmetria and dysdiadochokinesia (Table 1).

Ataxic hemiparesis following thalamic infarction and hypesthetic ataxic hemiparesis in thalamic hemorrhage and infarction have been reported ${ }^{17}$. Unilateral cerebellar ataxia was observed following contralateral thalamic infarction ${ }^{17}$. The lesion was located in the ventrolateral part of the thalamus, with involvement of the ventrolateral nucleus. From experimental evidence it was confirmed that the ventrolateral

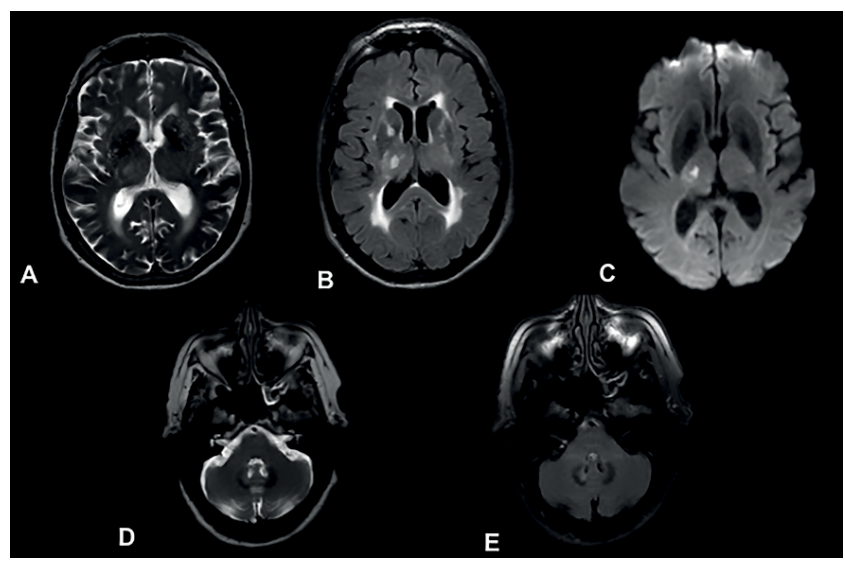

Figure 4. Axial T2 (A), FLAIR (B), and Diffusion weighted images (C) demonstrate foci of signal change in the right thalamus associated with expansion and restricted diffusion, consistent with a recent ischemic lesion. Hyperintensity on T2 (D) and FLAIR-weighted images (E) of the right dentate nucleus without diffusion restriction (not showed) suggestive of transaxonal degeneration. 
nucleus receives fibers from the contralateral cerebellar dentate nucleus (the dentatorubrothalamic projection) ${ }^{17}$.

\section{Chronic crossed cerebellar diaschisis}

A 15-year-old male undergoing outpatient follow-up for epilepsy related to a viral meningoencephalitis when he was one year old presented with right hemiparesis as a sequel, and a head MRI showed left temporal lobe encephalomalacia and contralateral cerebellar atrophy due to CCD (Figure 5).

Diaschisis means reduction of function of a part of the encephalon following the interruption at a remote site of an afferent pathway, which supply background excitation to the neurons, keeping them in a state of low activity ${ }^{18}$. The concept of crossed cerebral cerebellar diaschisis following lesions (usually described in strokes) to the motor cortex of one cerebral hemisphere was popularized by Baron et al. ${ }^{19}$. In the literature ${ }^{18}$, there is difference in side of cerebellar diaschisis (ipsilateral or contralateral) depending upon the age of onset of the cerebral injury ${ }^{18}$. It is suggested that the production of remote effects, such as crossed and uncrossed cerebellar diaschisis, could be closely related to maturation of the cortico-ponto-cerebellar tract in the developing brain during childhood ${ }^{18}$ Precocious cerebral injury, below one year, would be more likely to produce ipsilateral rather than contralateral cerebellar diaschisis ${ }^{18}$.

The effect on the cerebellum was one of reduction of blood flow and energy metabolism secondary to neuronal

Table 1. Clinical symptoms related to specific tract lesions.

\begin{tabular}{|c|c|}
\hline Tract & Symptoms \\
\hline $\begin{array}{l}\text { Dentate-rubro- } \\
\text { olivary tract }\end{array}$ & Oculopalatal tremor and tinnitus \\
\hline $\begin{array}{l}\text { Dentate-rubro- } \\
\text { thalamic tract }\end{array}$ & $\begin{array}{c}\text { Cerebellar mutism (cerebro-cerebellar } \\
\text { diaschisis) and loss of control of } \\
\text { voluntary movements }\end{array}$ \\
\hline $\begin{array}{l}\text { Cortico-ponto- } \\
\text { cerebellar tract }\end{array}$ & $\begin{array}{l}\text { Truncal ataxia; resting and } \\
\text { intentional tremor }\end{array}$ \\
\hline
\end{tabular}
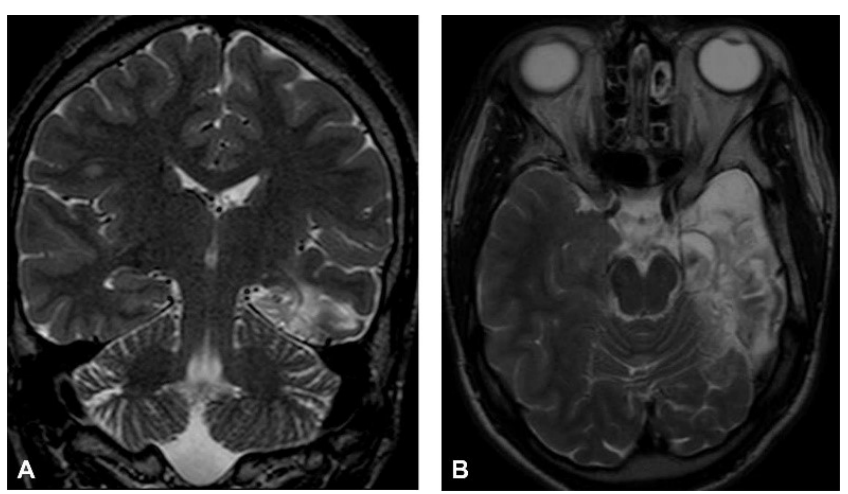

Figure 5. Axial T2 (A) weighted image shows encephalomalacia in the left temporal lobe, compatible with previous history of meningoencephalitis. (B) Coronal T2 weighted image: left temporal lobe encephalomalacia and contralateral cerebellar atrophy due to crossed cerebellar diaschisis. depression resulting from infarction of the opposite cerebral hemisphere. CCD has been studied in hemiplegic children mostly by functional neuroimaging like SPECT ${ }^{18}$.

Contralateral cerebellar hemisphere atrophy was also observed because of interruption of the cortico-ponto-cerebellar pathway that caused crossed cerebellar diaschisis. The latter involves functional loss of part of the brain after interruption of an excitatory afferent pathway ${ }^{18}$. In chronic crossed cerebellar diaschisis (CCD), this phenomenon is attributed to a reduction in the blood flow to and metabolism in the contralateral cerebellar hemisphere following interruption of the cortico-ponto-cerebellar tract ${ }^{18}$. The reduction in blood flow is believed to reflect decreased neuronal activity.

\section{Acute transient crossed cerebellar diaschisis}

An 18-year-old male patient had his first seizure a month prior to the imaging exam and since then presented constant and uncontrolled seizures. Head MRI showed a focus of hyperintensity localized in the left temporal lobe related to the epileptic state (Figure 6). In this case, the CCD was due to status epilepticus. A follow-up MRI performed one month later showed involution of the previously detected cerebral and cerebellar alterations. The patient is being followed up in an outpatient clinic to investigate the underlying cause of the epilepsy, but to date no cause has been found.

Initially described in the stroke literature, crossed cerebellar diaschisis may represent injury caused by excessive neuronal transmission from prolonged excitatory synaptic activity via the cortico-pontine-cerebellar pathways, that leads to an imbalance between energy hypermetabolism and blood supply and results in hypoxia and anerobic metabolism $^{19,20,21,22}$.

The cerebellar hemispheres are intimately connected to the contralateral cerebral cortex through feedback pathways that regulate motor function. Cerebellar afferent synapses

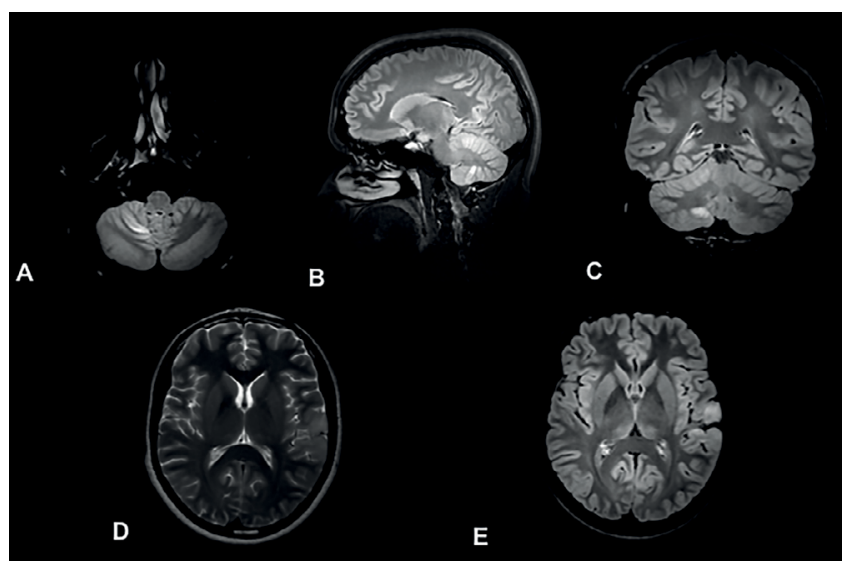

Figure 6. Axial (A), sagittal (B), and coronal (C) FLAIR weighted images: Focal hyperintensity in the anteroinferior portion of the right cerebellar hemisphere. Axial T2(D) and FLAIR weighted images (E) Cortical hyperintense focus in the left temporal lobe, with restricted diffusion (not shown) corresponding to status epilepticus. Crossed cerebellar diaschisis. 
reach the cerebral cortex via the cerebellar-dentate, dentaterubral (crossed), rubro-thalamic and thalamo-cortical pathways. Cerebral motor cortex afferent synapses tend to modulate the cerebellar control of motor function through the cortico-ponto-cerebellar pathway ${ }^{20,23,24,25}$.

Postical brain MRI can show a wide range of abnormalities reflecting physiological and pathological alterations due to seizure. Lesions may also involve the epileptogenic region, as well as remote structures possibly related to the seizure propagation ${ }^{20}$. Classically affected regions are the hippocampus, basal ganglia, corpus callosum, neocortex, subcortical white matter, and, in rare cases, the cerebellum, manifesting as classic $\mathrm{CCD}^{19,24}$. In most cases, these lesions regress and brain MRI is normal, as in the presented case, reinforcing the hypothesis that they correspond to seizure consequences and not their causes, reflecting transient cytotoxic and vasogenic edema associated to seizures ${ }^{19,24}$.

\section{Wallerian degeneration of the middle cerebellar peduncles}

The Wallerian degeneration of the middle cerebellar peduncles results from the decussation of axons in the pons. An infarct in the pons may affect the nuclei and the tracts in the pons, possibly leading to middle cerebellar peduncle degeneration ${ }^{26,27,28}$.

A 45-year-old female patient presented with symptoms of wake-up stroke with dysarthria and buccal rhyme deviation to the left. There was progressive worsening of the symptoms, evolving to complete hemiparesis on the right, with brachial predominance. The patient suffered from systemic arterial hypertension and type 2 diabetes, and was a smoker. A head CT and MRI revealed a left-sided hemi-pontine infarct. Both middle cerebellar peduncles were normal. A MRI six months later revealed a pons sequela and hyperintensity of both middle cerebellar peduncles (Figure 7), characteristic of Wallerian degeneration caused by interruption of the cortico-ponto-cerebellar pathways. Follow-up of the patient has revealed no new ischemic events or other complaints.

Wallerian degeneration involves the demyelination and disintegration of the distal portions of the axon after transection of or injury to the neuron ${ }^{26}$. Myelinated tracts show a loss of the cytoplasmic bands and longitudinal columns and their associated membrane pores ${ }^{29}$. Macrophage recruitment for myelin removal also takes place ${ }^{30}$. These events of demyelination lead to hyperintensity on T2 and FLAIR-weighted images. The middle cerebellar peduncle contains the fibers

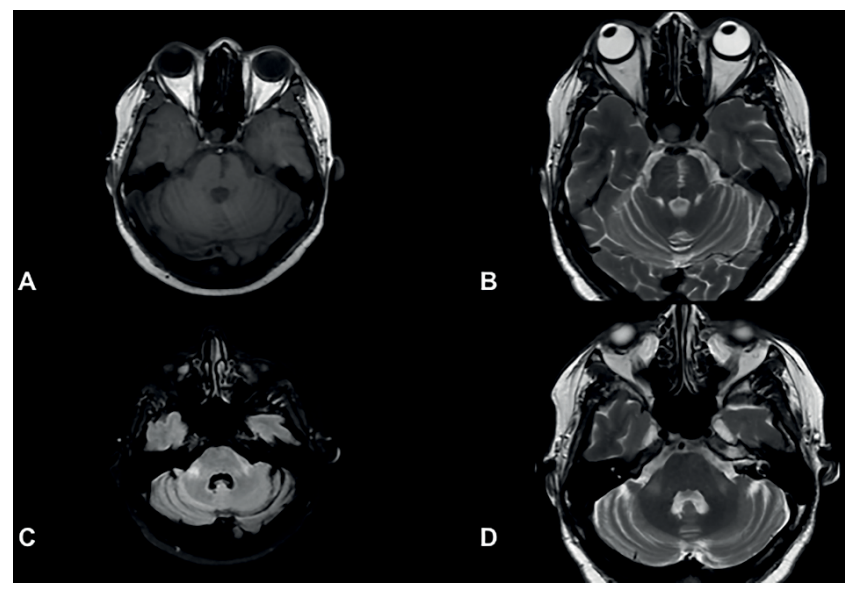

Figure 7. Axial T1 weighted (A) and T2 weighted images (B): MRI performed six months after the onset of the symptoms showed hyperintensity in the left hemi-pons, highly suggestive of infarct sequelae. Axial FLAIR (C) and T2 weighted images

(D): Hyperintensity of both middle cerebellar peduncles

suggestive of Wallerian degeneration caused by a pontine infarct.

of the cortico-pontine cerebellar tracts. These fibers originate in the contralateral pontine nuclei. Unilateral pontine lesions interrupt the ipisilateral cortico-pontine fibers and the crossing contralateral pontine-cerebellar fibers ${ }^{26}$. Such lesions explain why both middle cerebellar peduncles may be affected, as observed in this case. Wallerian degeneration of the middle cerebellar peduncles can present with ataxia after interruption of the pathways that connect the motor cortex and cerebellar hemisphere. Such interruption interferes with cerebellar functions such as movement planning and coordination ${ }^{27}$.

\section{CONCLUSION}

Cerebellar transaxonal degenerations result from the impairment of specific neuronal pathways and can be well characterized by conventional MRI and DTI. HOD is the only transaxonal degeneration that presents with increased volume of the affected structure. Several of these degenerations may have clinical repercussions, such as palatal myoclonus in HOD and ataxia in Wallerian degeneration of the middle cerebellar peduncles. Neurologists and radiologists need to become familiar with the diagnosis of these conditions since their presentations are peculiar and often subtle, and can easily be misdiagnosed as ischemic events, degenerative disease, demyelinating disease, or even tumors.

\section{References}

1. Gatlin J, Wineman R, Schlakman B, Buciuc R, Khan M. Hypertrophic olivary degeneration after resection of a pontine cavernous malformation: a case report.J Radiol Case Rep. 2011;5(3):24-9. https://doi.org/10.3941/jrcr.v5i3.603
2. Dinçer A, Özyurt O, Kaya D, Koșak E, Öztürk C, Erzen C, et al. Diffusion tensor imaging of Guillain-Mollaret triangle in patients with hypertrophic olivary degeneration. J Neuroimaging. 2011 Apr;21(2):145-51. https://doi.org/10.1111/j.1552-6569.2009.00461.x 
3. Wang H, Wang Y, Wang R, Li Y, Wang P, Li J, et al. Hypertrophic olivary degeneration: A comprehensive review focusing on etiology. Brain Res. 2019 Sep;1718:53-63. https://doi.org/10.1016/j. brainres.2019.04.024

4. Zhou C, Qin Z, Shen Y, Han N, Sui Y, Zhu Y, et al. Combined hypertrophic olivary degeneration and Wallerian degeneration of the bilateral middle cerebellar peduncles: a case report. Neurol Sci. 2019 Sep;40(9):1971-4. https://doi.org/10.1007/s10072-019-03858-8

5. Howard C, Arnold A, Brust T. An acute clinical presentation associated with hypertrophic olivary degeneration. Can J Neurol Sci. 2019 Jan;46(1):137-9. https://doi.org/10.1017/cjn.2018.375

6. Onen MR, Moore K, Cikla U, Ucer M, Schmidt B, Field AS, et al. Hypertrophic olivary degeneration: neurosurgical perspective and literature review. World Neurosurg. 2018 Apr;112:e763-e771. https:// doi.org/10.1016/j.wneu.2018.01.150

7. Venkatesh M, Chakkalakkoombil SV, Nair PP, Sowkar UB. Idiopathic bilateral hypertrophic olivary degeneration. BMJ Case Rep. 2017 Dec 22;2017. pii: bcr-2017-223115. https://doi.org/10.1136/bcr-2017223115

8. Rosenblum JS, Nazari M, Al-Khalili Y, Potigailo V, Veznedaroglu E. Unilateral symptomatic hypertrophic olivary degeneration secondary to midline brainstem cavernous angioma: a case report and review of the literature. World Neurosurg. 2018 Feb;110:294-300. https://doi. org/10.1016/j.wneu.2017.10.061

9. Kitajima M, Korogi Y, Shimomura O, Sakamoto Y, Hiria T, Miyayama H, et al. Hypertrophic olivary degeneration: MR imaging and pathologic findings. Radiology. 1994 Aug;192(2):539-43. https://doi.org/10.1148/ radiology.192.2.8029428

10. Tilikete $\mathrm{C}$, Desestret $\mathrm{V}$. Hypertrophic olivary degeneration and palatal or oculopalatal tremor. Front Neurol. 2017 Jun;8:302. https://doi. org/10.3389/fneur.2017.00302

11. Sabat S, Mannering N, Agarwal A. Hypertrophic olivary degeneration: Case series and review of literature. J Neurol Sci. 2016 Nov;370:180-6. https://doi.org/10.1016/j.jns.2016.09.055

12. Van Eetvelde R, Lemmerling M, Backaert T, Favoreel N, Geerts B, Sommeling C, et al. Imaging Features of hypertrophic olivary degeneration. J Belg Soc Radiol. 2016 Jul;100(1):71. https://doi. org/10.5334/jbr-btr.1065

13. Akar S, Drappatz J, Hsu L, Blinder RA, Black PM, Kesari S. Hypertrophic olivary degeneration after resection of a cerebellar tumor. J Neurooncol. 2008 May;87(3):341-5. https://doi.org/10.1007/ s11060-008-9523-7

14. Birbamer G, Buchberger W, Felber S, Aichner F. MR appearance of hypertrophic olivary degeneration: temporal relationships. AJNR Am J Neuroradiol. 1992 Sep;13(5):1501-3.

15. Araujo NA, Raeder MT, da Silva Junior NA, Oshima MM, Parizotto LO, Reis F. Hypertrophic olivary degeneration secondary to central tegmental tract injury. Radiol Bras. 2015 May-Jun;48(3):199-200. https://doi.org/10.1590/0100-3984.2014.0075
16. Meola A, Comert A, Yeh FC, Sivakanthan S, Fernandez-Miranda JC. The nondecussating pathway of the dentatorubrothalamic tract in humans: human connectome-based tractographic study and microdissection validation. J Neurosurg. 2016 May;124(5):1406-12. https://doi.org/10.3171/2015.4.JNS142741

17. Boiten J, Lodder J. Ataxic hemiparesis following thalamic infarction-case report. Stroke. 1990 Feb;21(2):339-40. https://doi. org/10.1161/01.str.21.2.339

18. Chakravarty A. MR evaluation of crossed and uncrossed cerebralcerebellar diaschisis. Acta Neurol Scand. 2003 Jul;108(1):60-5. https://doi.org/10.1034/j.1600-0404.2003.00039.x

19. Baron JC, Bousser MG, Comar D, Costaigne P. Crossed cerebellar diaschisis in human supratentorial brain infraction. Trans Am Neurol Assoc. 1981;105:459-61.

20. Hebant B, Louillet F, Verdure P, Le Couteulx S, Bouchaud L. Periictal transient MRI signal abnormalities with crossed cerebellar diaschisis due to status epilepticus. Rev Neurol (Paris). 2018 Dec;174(10):750-2. https://doi.org/10.1016/j.neurol.2017.10.017

21. Baradaran H, Omran S, Chazen JL. Teaching neuroimages: acute crossed cerebellar diaschisis. Neurology. 2016 Apr;86(14):e154-e155. https://doi.org/10.1212/ WNL.0000000000002544

22. Mahale R, Mehta A, Rangasetty S. Crossed cerebellar diaschisis due to rasmussen encephalitis. Pediatr Neurol. 2015 Sep;53(3):272-3. https://doi.org/10.1016/j.pediatrneurol.2015.03.015

23. Samaniego EA, Stuckert E, Fischbein N, Wijman CA. Crossed cerebellar diaschisis in status epilepticus. Neurocrit Care. 2010 Feb;12(1):88-90. https://doi.org/10.1007/s12028-009-9312-y

24. Massaro A. Teaching neuroimages: crossed cerebellar diaschisis in hemispheric status epilepticus. Neurology 2012; 79(20):e182-e182. https://doi.org/10.1212/WNL.0b013e318274de51

25. Cole AJ. Status epilepticus and peri-ictal imaging. Epilepsia. 2004;45 Suppl 4:72-7. https://doi.org/10.1111/j.0013-9580.2004.04014.x

26. Okamoto K, Tokiguchi S, Furusawa T, Ishikawa K, Quardery AF, Shinbo $S$, et al. MR features of diseases involving bilateral middle cerebellar peduncles. AJNR Am J Neuroradiol. 2003 Nov-Dec;24(10):1946-54.

27. Simone T, Regna-Gladin C, Carriero MR, Farina L, Savoiardo M. Wallerian degeneration of the pontocerebellar fibers. AJNR Am J Neuroradiol. 2005;26(5):1062-5.

28. Fitzek C, Fitzek S, Stoeter P. Bilateral Wallerian degeneration of the medial cerebellar peduncles after ponto-mesencephalic infarction. Eur J Radiol. 2004 Mar;49(3):198-203. https://doi.org/10.1016/ S0720-048X(03)00132-3

29. Abrahams PH, Day A, Allt G. The node of Ranvier in early Wallerian degeneration: a freeze-fracture study. Acta Neuropathol. 1981;54(2):95-100. https://doi.org/10.1007/bf00689401

30. Brück W, Friede RL. The role of complement in myelin phagocytosis during PNS Wallerian degeneration. J Neurol Sci. 1991 Jun;103(2):182-7. https://doi.org/10.1016/0022-510x(91)90162-z 